\title{
ICHD' 2018 The 13th International Conference on Hydrodynamics First Announcement
}

\author{
September 2-6, 2018 Sheraton Grand Inchecon Hotel Songdo, Incheon Korea
}

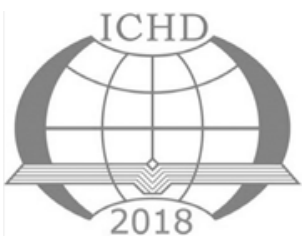

The 13th International Conference on Hydrodynamics (ICHD'2018) will be held in Incheon, Korea on 2-6 September, 2018.

The first International Conference on Hydrodynamics (ICHD) was initiated in 1994 in Wuxi, China. Since then, 12 more ICHD conferences were held in Hong Kong, Seoul, Yokohama, Tainan, Perth, Ischia, Nantes, Shanghai, St Petersburg, Singapore, and Egmond aan Zee. Evidently the ICHD conference has become an important event among academics, researchers, engineers and operators, working in the fields closely related to the science and technology of hydrodynamics. The coming ICHD'2018 conference will be hosted and organized by Seoul National University (SNU).

We invite you to join the 13th International Conference on Hydrodynamics, and all of you will be warmly welcome to Incheon, Korea.

\section{Conference Themes}

The conference will cover all issues related to all fields of hydrodynamics, including in ship and ocean engineering, mechanical engineering, and civil engineering. Specific themes include, but are not limited to:

- Theoretical hydrodynamics

- Linear and non-linear waves and current

- Ship and naval hydrodynamics, including resistance, propulsion, power, seakeeping, manoeuvrability, slamming, sloshing, impact, green water, wake flow,...

- Cavitations and cavity flow

- Ocean, coastal engineering

- Fluid-structural interactions and hydroelasticity

- Hydraulic engineering

- Industrial fluid dynamics

- Computational fluid dynamics(CFD)
- Ocean and atmosphere dynamics

- Environmental hydrodynamics

- Advanced experimental techniques

Particularly we Strongly encourage the participation from non-marine engineering fields, which as mechanical, civil, aero and bio fluid engineering

\section{Abstract Submission}

Abstract (200-400 words) can be submitted through website or by e-mail to ICHD2018@snu.ac.kr before the due date. The acceptance of abstract will be noticed by E-mail.

Key Dates:

\begin{tabular}{cc}
\hline Receipt of abstract & November 30, 2017 \\
\hline Provisional acceptance & January 31, 2018 \\
\hline Receipt of full papers & April 30, 2018 \\
\hline Final acceptance & May 31, 2018 \\
\hline $\begin{array}{c}\text { Preliminary programme } \\
\text { and early registration }\end{array}$ & June 30, 2018 \\
\hline Final programme & July 31, 2018 \\
\hline Conference & September 2-6, 2018 \\
\hline
\end{tabular}

Organization:

Conference Chair: Prof. Yonghwan Kim (Department of Naval Architecture \& Ocean, Engineering, Seoul National University)

Sponsoring Organizations:

- Lloyd's Register Foundation Center at SUN (LRFC)

- Advanced Marine Engineering Center

- College of Engineering, Seoul National Univeraity

\section{Contants us:}

\section{Secretariat of ICHD 2018}

Advanced Marine Engineering Center, Seoul

National University

E-mail: ICHD2018@snu.ac.kr

Tel: +82-2-880-2599, Fax: +82-2-876-9226

Website: http://mhl.snu.ac.kr/ichd2018 (will be available from July, 2017) 